\title{
Some New Viewpoints in Botany*
}

\author{
K. L. Jones \\ Department of Botany, University of Michigan, Ann Arbor, Michigan
}

Viewpoints depend on one's present horizons. As an individual botanist, without aid of questionnaires, I bring to your attention what to me are some significant viewpoints along the research front. I confess sharing Byron T. Shaw's (1961) prediction, "Recent events suggest that great discoveries in biology are imminent." And with certain reservations, I too like to think, "The high promise of the life sciences is that the biological nature of life itself may be discovered and defined. Man must learn to use biological knowledge to plan his own destiny. His future depends on it."

I have selected seven viewpoints and will present them, without order of priority, in an "unnatural" sequence. This may prevent me from lingering in one area of inquiry overlong of this somnolent day after Thanksgiving.

\section{Controlled environments as a clue to plant behavior.}

How many of you have visited the pioneer controlled environmental installation at Pasadena-Caltech's Phytotron? The new Climatron, developed also by Dr. Frits Went, at the Shaw Gardens, St. Louis? Well since none of you have, I will try to bring this subject closer by relating my own first visit to the Phytotron. It was at a time when there was a serious attempt to prevent the introduction of fungous spores and other microbial life into the installation. Visitors were required to put on freshly laundered coveralls of the Dr. Denton cut. They were apparently of one size which gave me the wistful appearance of "Dopey" in Snow White and the Seven Dwarfs. I tripped my way through a labyrinth of cubicles each with unique environmental regimes. An experimenter from Israel was conducting a series of experiments wherein ordinary garden crops were receiving water only on their leaves as mist. It seems that there was presumptive evidence that the heavy dews in Isreal were permitting some mesophytic plants to survive in spite of the low soil moisture. In the Phytotron the plants were projecting from glass retorts, with their roots sealed off but visible in the dry empty containers. Water absorbed as mist by the leaves circulated downward into the roots where in several instances sufficient liquid had been excreted to more than half fill the retort - a sort of transpiration stream in reverse. The absorption of water from leaves is now well known and in fact it is a standard prac-

\footnotetext{
* Paper presented at the Convention of the Central Association of Science and Mathematics Teachers, Chicago, Illinois, November 24, 1961.
} 
tice to feed dissolved mineral by sprays, particularly where soils immobilize minor elements such as zinc and copper.

Elaborate controlled environmental facilities such as the Caltech Phytotron are prohibitively expensive for general use. It will interest you to know that our federal government has excellent installations of this nature at Beltsville, Maryland which Mr. Khrushchev inspected and that France, for example, has quite a lavish one as does I believe Australia. To study the interplay of numerous environmental factors on the growth, reproduction and fruiting of plants is of great significance both theoretically and in agriculture and forestry. It is now fashionable for botanical departments in colleges and universities and private industry using plant products to have controlled environmental chambers that are quite remarkable in their sensitivity. These are a boon to the physiologist of whole plants and the ecologist.

As one example of the tantalizing problems that controlled environmental chambers can help explore, let me mention endogenous rhythms, for reference see: Brown, Frank A. Jr. (1959). These include daily rhythms of cell-division, growth rate and sleep-movement. The problem here is whether the plants have independent internal "clocks" which register the various natural periods, without the need for external sources of information, or are the pervasive geophysical factors (as yet largely obscure) the primary "clocks" which provide reference frequencies for timing the endogenous rhythms?

\section{Quantitative taxonomy.}

I am told on good authority that botanical taxonomy is going quantitative. This means all the way out-computers! For some of us who associate taxonomy with field botany and natural history, this prospect is cold and decidedly stultifying. Not being a professional taxonomist I am going to give my thin vote to quantification because I believe in the potential of computers and such when used by intelligent botanists in the interpretation of multivariates. This will save time and be especially useful in difficult delineations. I cannot conceive of it being the working tool in general taxonomic studies. There are several ways of knowing each of a thousand sheep. One way is to get measurements of numerous characters and work out a mechanical scheme so that you know that you now have before you "sheep-number-783." Another way is the shepherds'!

I am pleased (as a microbiologist) to hear from an outstanding plant taxonomist that one of the clearest statements of the new viewpoint of quantitative taxonomy is that of the microbiologist P. A. A. Sneath (1961) as reported in the journal Systematic Zoology.

"What is the outlook for systematics. I feel sure it will soon become a quantitative science, and will be closely linked to logic, informa- 
tion theory and statistics. The field of systematics will certainly widen to include entities like genes, enzymes, and even chemical substances, and of course such life as we may one day discover on other planets. Taxonomic techniques based on multivariate analysis will be increasingly used in fields such as medicine, ecology, pedology and information retrieval, for in all these we have the basic problem of taxonomy - to array complex entities, whether they are diseases, vegetation, soils or documents into 'natural' groups."

All of the methods are based on elementary forms of multivariate analysis. They compare every organism with every other organism in the study, and then produce a figure which represents an estimate of overall similarity for each of the comparisons between pairs of organisms. Each method employs as many characters as possible, and for practical purposes they all need electronic computing machines to do the extensive but repetitive calculations.

The computer field has opened the philosophical question of the relation between automata and living systems.

\section{Palynology.}

The science of the study of spores, including pollen has burgeoned in part because it is recognized that pollen analysis provides a much more representative picture of the pleistocene flora of a region than do macrofossils, such as leaves, seeds and wood.

I find relatively few of my students are familiar with the origin of the stratified layers of pollen which occur in peat bogs and lake sediments as wind-borne pollen each year rains over the earth falling equally on the just and unjust. This benign, natural "fall-out" settles in bogs in particular and has done so for thousands of years with the highly refractory grains undergoing little alteration under the anaerobic conditions of acid bog waters. Here the palynologist (or yourself or myself if driven to it) may take borings to obtain cores of peat containing, amidst the Sphagnum, the layers of microfossils. By chemical treatment (recipe on request!) the pollen may be extracted and concentrated for study and identification. The size, structure, shape and sculpturing of grains of a given species are relatively constant and furnish excellent means of identifying the prevailing plants. For example, Juglans cinerea and $J$. nigra are similar except for the number of pores, 9 in the former and 14 in the latter. Note this tidbit: fossil remains from Kalamazoo County, Michigan, of a Musk Ox identified by Professor Claude Hibbard were associated with marl, which the palynologist, Professor William Benninghoff, (1961) determined to contain primarily pollen of spruce. So the Musk Ox, which from carbon 14 dating died 13,000 years ago, roamed in a spruce forest. 
The ecologist gets a new dimension in his work as he takes the viewpoint of palynology. Present day communities come to be associated historically with those of the pleistocene as it is possible to relate most of the pollen types with modern vegetation. This viewpoint has gained sufficient acceptance to evoke the first international congress in palynology-ecology which will be held in Germany this spring.

Macrofossil deposits usually represent specialized environments such as river-bottoms or forest swamps. Upland forest and vegetation types are usually inadequately represented, if at all. Pollen diagrams, on the other hand, permit the investigator to depict the kind of flora in the upland as well as the vegetation immediately surrounding the deposit.

In the past 5 years newly discovered pollen flora in Northwest America, Northeast Asia, and Japan have brought to light evidence pertaining to the history of these regions in the late Cenozoic Period. This evidence contributes to the understanding of the origin of Arctic and Boreal floras.

\section{Biological synthesis.}

"John Q Public" is confused about biological synthesis partially because journalists reporting on such matters, as the creation of DNA and photosynthesis in a test tube, are confused.

Man has not made DNA, starting from raw materials alone, such as nucleotides; nor has he accomplished photosynthesis in a test tube from man-made chemicals. In both situations experimentalists have performed the remarkable feat of biological synthesis which is an unusual viewpoint indeed. Here one extracts or removes from living cells certain components, such as chloroplasts or mitochondria, and exploits their powers. By sonic vibration it is possible to break open the cells, as you know, and extract organelles or even lesser particulates such as enzymes and proceed to collect these in quantity and centrifuge them out in rather clean condition. In proper juices, they may be made to perform functions which occur ordinarily in living protoplasm.

In the case of the gene-stuff DNA, a biological synthesis, may be effected if one brings together the nucleotides, or building units, by means of a proper organizing enzyme and a trace of intact DNA-but not otherwise. The organizing enzyme of course was not made by a chemist but was obtained from microbial cells, perhaps $E$. coli.

The photosynthetic pigment, chlorophyll, was chemically synthesized last summer in two laboratories-Harvard and one in Germany. This misled newspaper men to report that now "Science" could carry on photosynthesis in a test tube. This is very far from the facts. 
It is truly remarkable that chlorophyll has been made by man but it takes intake chloroplasts-the living organelles to perform photosynthesis. Chloroplasts are cytoplasmic bodies, as you all know, which bear the chlorophyll in elegant little grana which are in piles within a complex stroma. The chloroplasts carry on the light phase of photosynthesis in the grana and the dark phase in the stroma. The light phase involves the release of a high-level electron from a chlorophyll molecule due to the action of a photon of light energy. The electron falls back to its original level within a very short period of time, perhaps a hundred millionth of a second. The chloroplast catches the electron in its high-energy-state and lets it decline to its original level through its own machinery. The energy released is incorporated into ATP (adenosine triphosphate) and $\mathrm{TPNH}_{2}$ (reduced triphosphopyridine nucleotide). These high energy phosphates will propel the dark phase, wherein carbon dioxide is assimilated.

Thus we see that through biological synthesis selected phenomena which happen to be associated with living processes are analyzed. These remarkable experiments, made possible by modern instrumentation and skillful technicians, may of course be slightly overemphasized as the fundamental scientific approach. One must caution that a process is not a living thing. Rene Dubos of the Rockefeller Institute for Medical Research, (1961) a great experimenter puts this matter very wisely, "It is likely, however, that if the analytical breakdown of living things into simpler and ever simpler components is not supplemented by a more synthetic approach, it will lead the biologist into areas of knowledge concerned not with essential characteristics of life but with a few selected phenomena which happen to be associated with living processes. To accept this limitation is an attitude of intellectual security and may be the better part of wisdom, but it denies scientists the chance to gain deeper insight into larger biological realities."

\section{Radiation: an aid to plant improvement.}

I am afraid that this viewpoint will be somewhat of a let down. There is a great deal of misinformation to the effect that it is an easy matter to induce favorable mutations in plants and that by such techniques as radioactive isotopes man will soon greatly alter and improve his crops. Let us look at the evidence. In this country a cooperative program was established in 1952 at the Brookhaven National Laboratory, Long Island, N. Y., to enable plant breeders in the U. S. A. and foreign countries to use a broad spectrum of radiation techniques in their improvement programs. More than two hundred and fifty scientists in universities and agricultural experiment stations throughout the United States and in twenty-five foreign countries 
have participated in the work. Scientists in other countries have recognized the possible applications of radiation-induced mutations to the improvement of crop plants. The Swedish group has been singularly energetic.

At Brookhaven plants are grown in a two-acre gamma radiation field, in concentric rows around a central cobalt- 60 source. The field thus resembles a large target with the bull's-eye, the cobalt 60 .

Since the work was started in 1952 only six new varieties have been released to farmers of the world as a consequence of radiation experiments, according to Dr. Seymour Shapiro (1960) writing from Brookhaven. "Three of these new varieties were developed and released in Sweden, the country first to initiate such studies, on an intensive level. These radiation-produced varieties are 'Primex' white mustard, 'Regina II' summer oil rape, and the 'Weibull Stralart' fodder pea. A new bean, called 'Shafer's Universal,' has been released in Germany, and the 'Sanilac' navy bean and the ' $\mathrm{NC} 4 \mathrm{X}$ ' peanut are the results of efforts in Michigan and North Carolina respectively."

Now six new varieties in nine years is hardly changing the face of agriculture. The result should put a dash of realism into some of the extravagant propaganda such as: man is becoming, at long last, a stagehand in the direction of the drama of life.

I do not mean to belittle the efforts in this applied area which have been great and highly intelligent. The plain facts are that while it is easy to produce mutations by irradiation in higher plants, very few are directly useful. It is an arduous task to sort out the useful ones and incorporate them into valuable existing varieties. The total gene assemblage in any plant is indeed complex and the interactions diverse. Oftentimes the value of a new mutant is nullified by concomitant deleterious features from which the useful trait cannot be separated.

\section{Biophysics as a botanical approach.}

At the head of the experimental peck order proudly, some think arrogantly, stands biophysics.

A popular viewpoint in biophysics is to extoll the electron. Nobel Laureate Albert Szent-Györge writes (1961) "Biochemistry, till now, occupied itself, chiefly, with molecules. I am profoundly convinced that to get to the bottom of things we must descent one dimension lower, to the electron. I do not think that these electrons disappear from the scene when their energy is invested into ATP. I believe that as ATP is formed by investing electronic energy, so electronic energy comes out from ATP again when the ATP drives our cell life. I do not doubt that these little electrons hold the secret to the most important and difficult biological processes." 
I read in that highly useful "Encyclopedia of Biological Sciences," edited by Peter Gray (1961) that, "The ultimate in the approach of biophysics would be to write down an equation and boundary conditions for a given living system. The solution of the equation subject to the boundary conditions would then predict the future behavior of the organism."

Now Professor Harold J. Morowitz the writer of the biophysics section in the "Encyclopedia" does, fortunately as I see it, admit that this is an idealized approach - there have been experimentalists lacking in a sense of humor. He says, "We might start on the one hand from our knowledge of nuclei and electrons, proceed to the formation of chemical bonds and understand the physics of small molecules. We might next investigate the polymers of these small molecules and proceed in an attempt to conceptually synthesize a cell and an organism from its atomic constituents."

"We might of course start from the other point of view, the phenomenological observations of living things."

Now, however one evaluates these statements of ardent biophysicists, whether he too believes "these little electrons hold the secret to the most important and difficult biological processes" or on the contrary considers the electron approach only one valid level of inquiry and that the whole organism is, for example, another of equal importance and difficulty, the fact remains that some very interesting new findings are emerging from this new viewpoint of biophysics as applied to plants.

As an example may I mention the superb studies of Dr. H. A. Borthwick and Dr. Sterling Hendricks (1960), on the photoreversible pigment which influences such diverse plant responses as seed germination, lengthening of stems, flowering and pigment production. All these phenomena exhibit action maxima, one in the red part of the spectrum near $6500 \AA$ and another in the far-red part near $7300 \AA$. The photoreaction is reversible, the red light driving it in one direction and the far-red driving it back. The photoreversible pigment is intensely blue in its red-absorbing form but its concentration is so low in the plant that it imparts no visible color. In fact it may be present in an albino corn plant at normal concentrations for stem growth, $<10^{-7}$ molar, a value too low to permit its detection by ordinary laboratory spectrophotometers.

\section{Unicells at work for man.}

Your students have no doubt made it clear that the newspapers and weeklies are playing up the unicells, especially the algae, in the great spectacle of space travel. I shall not add to this melodrama. Other items of the unicells at work for man do occasionally hit the public 
presses. I must admit that I am personally intrigued by the account in Newsweek, November 6, 1961 in which a hint is given of the classified work of Dr. Carson H. Rohrback under a Navy contract where two of his devices using unicells, "are already turning out enough electricity to operate signal lights, and other equipment used by the Navy." A bio-ocean battery of bacteria (strain-classified) live on sulphates, sea-water plus some metal and have an output "of 5-10 watts enough to power submarine detection buoys floating freely in water."

A prospect for the immediate future which has not been widely publicized is the mass culturing of free cells of higher plants. It has been found by Tulecke and Nickell (1959) that free cells of, say, yams for example can be grown in fermentation tanks in the manner of molds in antibiotic production. In effect tissue of a higher plant becomes reduced to free, unattached, unicells-evolution in reverse. These freely separated but rapidly growing cells give off metabolites into the medium, some of which may be rare chemicals of use to man in medicine, nutrition or industry. The prospect of growing mixed cultures of cells derived from different species of higher plants where their products may reflect a mutual stimulation (synergism) is indeed a new viewpoint of significance.

Well, we have squandered a good bit of a lovely late fall afternoon together. Many of the things I have discussed here are far removed from my own research interests. In bringing you new viewpoints I have profited by exchanging notes with my colleagues who generously informed me of developments in their special areas. I shall be happy to furnish further information through this good association of working scientists if any of you would like to explore further into the new botanical viewpoints herein presented. Thank you sincerely for the opportunity to be with you.

\section{Literature Cited}

Benninghoff, WM. S., and Hibbard, Claude. 1961. Fossil Pollen Associated with a Late-Glacial Woodland Musk Ox in Michigan. Mich. Acad. of Sci., Arts, and Letters. 46: 155-159.

Borthwick, H. A., AND Hendricks, S. B. 1960. Photoperiodism in Plants. Growth is controlled by light and the measurement of night length through reversible pigments. Science. 132: 1223-1229.

Brown, Frank A., JR. 1959. "Living Clocks." Science. 139: 1535.

Dubos, Rene. 1961. The Dreams of Reason. Science and Utopias. Columbia Univ. Press, 167 pp.

Gray, Peter. 1961. "Encyclopedia of Biological Sciences." Reinhold Publishing Corporation, New York. 1119 pp.

ShapIRo, Seymour, 1960. Radiation: An Aid in Plant Improvement. The Garden Journal. 10: 167-170.

Shaw, Byron T. 1961. Promise of the Life Sciences. Edited by Marguerite Gilstrap. U. S. Dept. of Agri. Graduate School. 
Sneath, P. A. A. 1961. Recent Developments in Theoretical and Quantitative Taxonomy. Syst. Zoology. 10 (3): 118-139.

Szent-Györge, Albert. 1961. Biological Transformations of Energy. pp. 5-15 in Promise of the Life Sciences. Edited by Marguerite Gilstrap. U. S. Dept. of Agri. Graduate School.

Tulecke, W. ANd L. S. NickedL. 1959. The production of large amounts of plant tissue by submerged culture. Science. 131.

\section{Problem Department}

\section{Conducted by Margaret F. Willerding \\ San Diego College, San Diego, Calif.}

This department aims to provide problems of varying degrees of difficulty which will interest anyone engaged in the study of mathematics.

All readers are invited to propose problems and to solve problems here proposed. Drawings to illustrate the problem should be well done in India ink. Problems and solutions will be credited to their authors. Each solution or proposed problem sent the Editor should have the author's name introducing the problem or solution as on the following pages.

The editor of the Department desires to serve her readers by making it interesting and helpful to them. Address suggestions and problems to Margaret F. Willerding, San Diego State College, San Diego, Calif.

\section{SOLUTIONS AND PROBLEMS}

Note. Persons sending in solutions and submitting problems for solution should observe the following instructions.

1. Solutions should be in typed form, double spaced.

2. Drawings in India ink should be on a separate page from the solution.

3. Give the solution to the problem which you propose if you have one and also the source and any known references to it.

4. In general when several solutions are correct, the one submitted in the best form will be used.

\section{LATE SOLUTIONS}

2797, 2798. Brother Alfred, St. Mary's College, Calif. 2798, 2801, 2803, 2804, 2805, 2806, 2807. Glenn E. Engebretsen, Playa del Rey, Calif.

2801. Ronald S. McCuiston.

2803, 2805, 2807. Dale Woods, Kirksville, Mo.

2803. J. W. Lindsey, Amarillo, Texas.

2805. C. W. Trigg, Los Angeles, Calif.

2806. Bob Lumpkins, Birmingham, Ala.

2807. El C. Callaway, Pittsburgh, Pa.

2807. Sam Bright, Austin, Texas. 